\title{
Surface Modification of Electrospun PVDF/PAN Nanofibrous Layers by Low Vacuum Plasma Treatment
}

\author{
Fatma Yalcinkaya, Baturalp Yalcinkaya, Adam Pazourek, Jana Mullerova, \\ Martin Stuchlik, and Jiri Maryska
}

Centre for Nanomaterials, Advanced Technologies and Innovation, Technical University of Liberec, Studentska 2, 46117 Liberec, Czech Republic

Correspondence should be addressed to Fatma Yalcinkaya; yenertex@hotmail.com

Received 19 May 2016; Accepted 21 July 2016

Academic Editor: Vitor Sencadas

Copyright (C) 2016 Fatma Yalcinkaya et al. This is an open access article distributed under the Creative Commons Attribution License, which permits unrestricted use, distribution, and reproduction in any medium, provided the original work is properly cited.

\begin{abstract}
Nanofibres are very promising for water remediation due to their high porosity and small pore size. Mechanical properties of nanofibres restrict the application of pressure needed water treatments. Various PAN, PVDF, and PVDF/PAN nanofibre layers were produced, and mechanical properties were improved via a lamination process. Low vacuum plasma treatment was applied for the surface modification of nanofibres. Atmospheric air was used to improve hydrophilicity while sulphur hexafluoride gas was used to improve hydrophobicity of membranes. Hydrophilic membranes showed higher affinity to attach plasma particles compared to hydrophobic membranes.
\end{abstract}

\section{Introduction}

The applicability of nanofibres to daily life is increasing day by day. Nanofibres can be defined as a fibre smaller than $1,000 \mathrm{~nm}$ according to [1-3]. There are several advantages of nanofibres compared to common textile fibres [4-6]. Nanofibres have the huge surface area, high aspect ratio, small pore size, and extremely high porous structure. These features bring high-tech applications for their end use. Nanomaterials are a good candidate for application in areas such as filtration [7-10], wound dressing [11-13], tissue engineering [14, 15], artificial vessels $[16,17]$, drug delivery systems $[18,19]$, acoustic materials [20-22], cosmetics [23], lithium ion batteries [24, 25], distillation [26], and desalination [27].

Almost all nanofibre structures are naturally hydrophobic. Both hydrophilic and hydrophobic nanofibres have important applications. Hydrophobic nanofibre membranes are promising for application in areas such as membrane distillation [28-30], drug delivery system [31], and electrical devices [32-34]. Increasing the hydrophilic properties of nanofibres will improve the permeability of nanofibre layers for water filtration [35-37], microfiltration [38], seeding or attaching the cells on the surface of the layer [39-41], moisture absorbing $[42,43]$, the release of proteins [44], and so on.

Polyvinylidene fluoride (PVDF) is one of the most commonly used polymers in electrospinning systems for producing nanofibre layers due to their easy processing and good mechanical/chemical properties. PVDF is a very hydrophobic material. PVDF is highly insoluble and has a high thermal stability, good chemical resistance, and good electrical properties resulting from the polarity of alternating groups on the polymer chain.

Another common material for the electrospinning process is polyacrylonitrile (PAN). PAN nanofibres are hydrophobic but not as much as PVDF fibres. PAN has a highly polar group, which is attractive for water and makes PAN less hydrophobic than PVDF.

The mechanical properties of nanofibres are not sufficient for their application so a supporting layer is necessary for their end use. Lamination of nanofibres to a supporting surface is quite challenging. Knowledge of engineering as well as chemistry is necessary for the lamination of nanofibres onto a suitable substrate.

In this work, both PVDF and PAN polymer solutions and their mixtures were electrospun. The electrospun nanofibres 
were laminated on a supporting layer to enhance their mechanical properties, and their contact angle was measured. Highly hydrophobic and hydrophilic nanofibre composite layers were subjected to low plasma vacuum treatment to change their hydrophobicity. The hydrophilicity of the materials is increased using atmospheric gas plasma treatment. Otherwise, sulphur hexafluoride $\left(\mathrm{SF}_{6}\right)$ was used to enhance the hydrophobicity of the materials. The polymer structure effect on the hydrophobicity/hydrophilicity of the material was evaluated.

Results are promising for an understanding of the effect of plasma treatment on hydrophilic PAN, hydrophobic PVDF, and PVD/PAN nanofibre layers. The polymer mixture has the combined advantages of both PAN and PVDF polymers in various ratios. New materials were designed according to desired hydrophilicity and thermal properties. The chemical structure of the fabricated nanofibres was analysed by Fourier transform infrared (FTIR) spectroscopy measurements.

\section{Experimental}

2.1. Materials and Equipment. Polyacrylonitrile (PAN) with an average molecular weight $(\mathrm{Mw})$ of $150 \mathrm{kDa}$ was purchased from Dimachema Pigment Corporation; N,N-dimethylformamide (DMF) and dimethylacetamide (DMAc) were purchased from Penta s.r.o; polyvinylidene fluoride (PVDF) was purchased from Solef. The supporting layer, a polyethylene/polypropylene (20/80) spunbond nonwoven bicomponent, was obtained from Pegas Nonwovens.

The zero-shear viscosity of the polymer solutions was measured using a Fungilab Expert viscometer at $23^{\circ} \mathrm{C}$.

The average fibre diameter and diameter distribution were analysed using a scanning electron microscope (SEM, Tescan Vega3 SB). All of the samples were coated with a $7 \mathrm{~nm}$ layer of gold before SEM imaging. The Image-j software was used to measure the average fibre diameter from more than 100 randomly selected fibres. A Schut digital micrometer was used to gauge the thickness of the layers.

The contact angle was measured at different places on the samples at room temperature using a Kruss Drop Shape Analyzer DS4. A total of $2 \mu \mathrm{L}$ of distilled water was put on the surface of a clean and dry membrane surface, and the average values were calculated.

Fourier transforms infrared spectroscopy (FTIR, Nicolet iZ10 by Thermo Scientific) was used to determine the mixture of PVDF/PAN nanofibres. Thermogravimetric analysis was performed to characterize the thermal stability in nitrogen atmospheres at a heating rate of $10^{\circ} \mathrm{C} / \mathrm{min}$ from room temperature to $700^{\circ} \mathrm{C}$ with TA Instruments TGA Q500.

A low vacuum MF plasma system consisting of an MW generator with a radiofrequency of $2.45 \mathrm{GHz}, 120$-second treatment time, and working pressure of $100 \mathrm{~Pa}$. was used in this study. Argon was used as the carrier gas, and $\mathrm{H}_{2}$, $\mathrm{O}_{2}$, and $\mathrm{N}_{2}$ were used for hydrophilic samples, and sulphur hexafluoride $\left(\mathrm{SF}_{6}\right)$ was used for hydrophobic samples as the reactive gasses.

2.2. Preparation of the Nanofibre Layer. $12 \% \mathrm{wt}$. PVDF polymers were mixed with DMAc/Acetone (4/1) solvents; $8 \%$ wt.
TABLE 1: Viscosity and mixing ratio of PVDF/PAN solutions.

\begin{tabular}{lcc}
\hline Sample name & PVDF/PAN ratio & Viscosity in $\mathrm{mPa} \cdot \mathrm{s} @ 23^{\circ} \mathrm{C}$ \\
\hline S1 & $2 / 1$ & 718 \\
S2 & $1 / 1$ & 499.3 \\
S3 & $1 / 2$ & 348.5 \\
S4 & $1 / 0$ & 969.3 \\
S5 & $0 / 1$ & 190.9 \\
\hline
\end{tabular}

PAN was mixed with the DMF solvent for $24 \mathrm{~h}$. The mixtures were prepared using the $12 \%$ wt. PVDF and $8 \%$ wt. PAN at a weight ratio of PVDF/PAN-1/0, 2/1, 1/1, 1/2, and 0/1. New solutions were mixed for $24 \mathrm{~h}$ after the mixture of PVDF/PAN solutions.

All of the solutions were electrospun using Nanospider NS-Lab equipment under stable conditions. The working mechanism of the Nanospider equipment was explained in detail in the literature [45-51]. A fusing machine (Meyer Mini Fusing Equipment/Germany) with applied heat and temperature was used for laminating the materials.

\section{Results and Discussion}

3.1. Solution Properties. Table 1 shows the viscosity and abbreviations according to the ratio of the solutions.

Viscosity of the solution is mainly affected by the concentration, molecular weight of the polymer, or additives. Solution viscosity is an effective parameter on the diameter of the nanofibres. Herein, the $12 \%$ wt. PVDF solution has almost 5 times higher viscosity than $8 \%$ wt. PAN due to its higher concentration or/and molecular weight.

3.2. Structural Characterization. The FTIR spectra were used to determine the structural characterization of PAN, PVDF, and the mixture of PVDF/PAN. TGA measurement of the samples before lamination and plasma treatment was performed. Figure 1 depicts the FTIR spectra of samples S1 to S5 with all of the characteristic transmission peaks from 630 to 3,350 .

As is seen in Figure 1, the prominent peaks for PAN around $2,923 \mathrm{~cm}^{-1}, 2,240 \mathrm{~cm}^{-1}, 1,735 \mathrm{~cm}^{-1}$, and $1,664 \mathrm{~cm}^{-1}$ are assigned to the stretching vibrations of the $-\mathrm{CH},-\mathrm{C} \equiv \mathrm{N}$, $-\mathrm{C}=\mathrm{O}$, and $-\mathrm{C}=\mathrm{N}$ groups, respectively, whereas the peak at $1,452 \mathrm{~cm}^{-1}$ corresponds to the bending vibration of the $-\mathrm{CH}_{2}$ group [52-58]. The characteristic peak of the nitrile groups around $2,240 \mathrm{~cm}^{-1}$ (stretching vibration) significantly decreased, when the amount of PVDF increased. For the PVDF samples, the band at $1,173 \mathrm{~cm}^{-1}$ is associated with the symmetrical stretching of the $-\mathrm{CF}_{2}$ group, which is a characteristic peak of PVDF in the polymer blend of PVDF/PAN. Another characteristic absorption band of PVDF at $876 \mathrm{~cm}^{-1}$ is attributed to the $\mathrm{C}-\mathrm{F}$ stretching vibration of the amorphous phase $[59,60]$.

3.3. Thermal Properties. The thermogravimetric analyses of PVDF, PAN, and PVDF/PAN nanofibres are shown in 


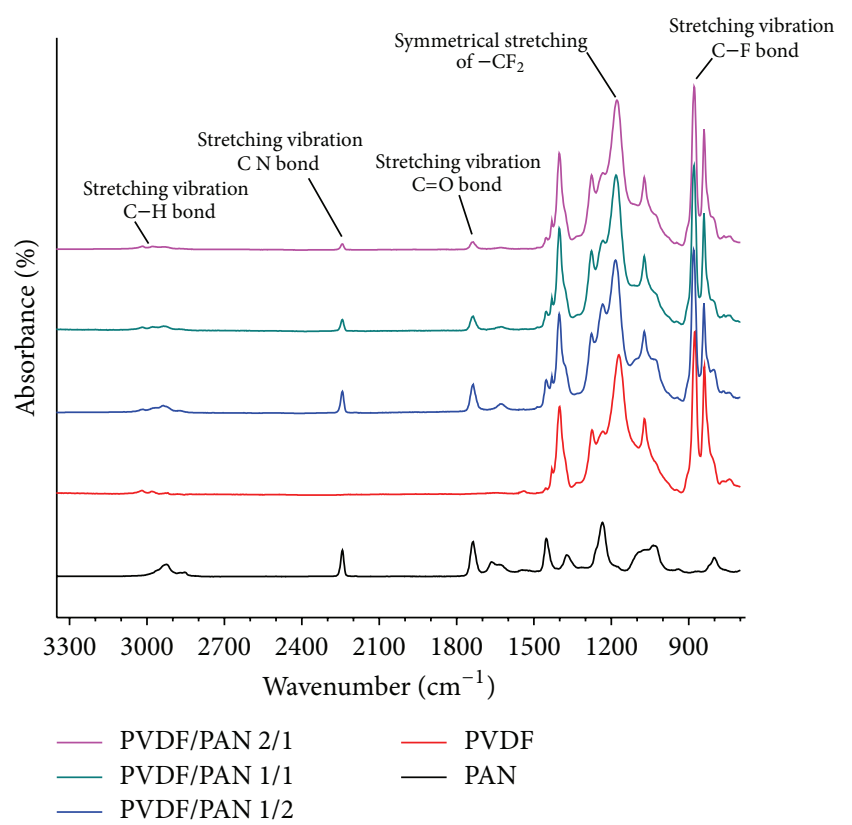

FIGURE 1: FTIR spectra of PVDF, PAN, and mixtures of PVDF/PAN nanofibres.

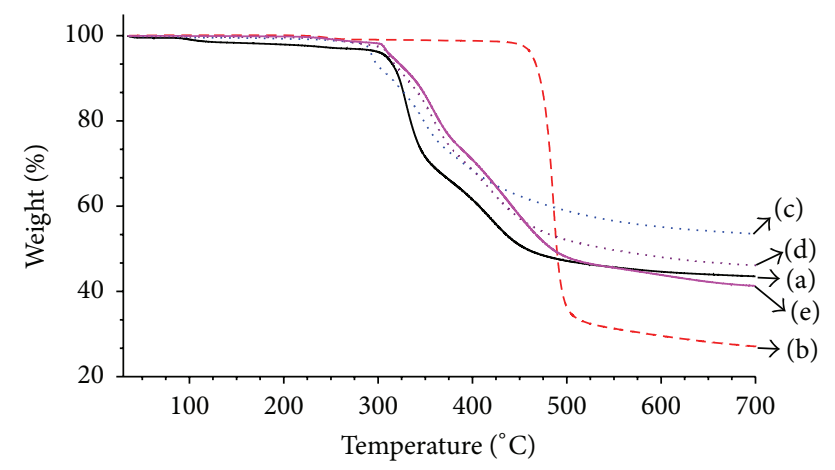
(a) - PAN
(d) $\ldots . . \quad$ PVDF/PAN $1 / 1$
(b) - - PVDF
(e) — PVDF/PAN 2/1
(c) $\cdots .$. PVDF/PAN $1 / 2$

Figure 2: TGA thermograms for PVDF, PAN, and mixtures of PVDF/PAN nanofibres.

Figure 2. PAN fibres decompose abruptly in the range of $280-$ $330^{\circ} \mathrm{C}$ and $450-480^{\circ} \mathrm{C}$ for PVDF fibres. Figure 2 indicates that the temperature of degradation of PVDF/PAN nanofibres significantly increases when the ratio of PVDF increases in the mixture. The PVDF/PAN nanofibres start to decompose at lower temperatures than the PVDF nanofibres. The degradation profile of the PVDF/PAN nanofibres is quite similar to the case of PAN. Adding PVDF changed the thermal stability of the fibres.

The thermal stability of PVDF was higher than PAN, whereas the char formation is lower. The more char formation in the case of PAN could be due to a reaction of the nitrile groups with adjacent groups, whereby promoting more char formation.
TABLE 2: Area weight of nanofibres and the thickness of the nanofibre composite membranes.

\begin{tabular}{lcc}
\hline Sample & $\begin{array}{c}\text { Thickness of composite } \\
\text { in } \mu \mathrm{m}\end{array}$ & Area weight in $\mathrm{g} / \mathrm{m}^{2}$ \\
\hline S1 & 63 & 5.21 \\
S2 & 57 & 4.35 \\
S3 & 56 & 3.96 \\
S4 & 68 & 5.50 \\
S5 & 56 & 2.99 \\
\hline
\end{tabular}

\subsection{Morphology of the Samples}

3.4.1. SEM Images. The surface structures of the nanofibrous composite materials were determined using SEM images. Figure 3 shows the SEM images at 10kx magnification of the surface of the PVDF, PAN, and PVDF/PAN nanocomposite membranes before and after the lamination process.

When comparing the SEM images, the PVDF nanofibre layers have a thicker fibre diameter and diameter distribution than the PAN nanofibres. The difference is almost twofold. The highest viscosity of the polymer solutions has the highest fibre diameter. It was found that a smaller fibre diameter yields a better filtration efficiency of nanofibre webs [61]. Additionally, it was observed that the lamination process did not change the fibre diameters of either the PVDF or PAN nanofibre webs.

3.4.2. Area Weight and Thickness of the Composite Materials. The area weight of the nanofibres is calculated by cutting the samples into $10 \times 10 \mathrm{~cm}^{2}$ and measuring the weight. The results are shown in Table 2 in $g / \mathrm{m}^{2}$. The thickness of the nanofibrous webs was measured after the lamination process (Table 2).

PVDF nanofibres have a higher area weight than PAN under the same spinning conditions. Increasing the amount of PVDF in the PVDF/PAN mixture increases the area weight of the nanofibre layers. The thickness of the composite material depends on the thickness of the supporting layer and the nanofibre web. It is evident from the table that the highest area weight of the PVDF sample has the highest layer thickness. The thickness of the layer is an important parameter for air and water filtration. Li et al. found that the filtration efficiency of the nanofibrous composite filter media for nanoparticles was increased along with the thickness of the nanofibre mats [62]. In another work, it was suggested that decreasing the fibre diameter and the thickness of the nanofibre layer results in an increase in the flux together with high salt rejection [63]. For water treatment applications, the area weight and the thickness of the nanofibre web could be adjusted according to the desired combination of rejection and flux.

3.4.3. Contact Angle. PAN is a semicrystalline polymer with high polar nitrile groups possessing a high dipole moment. The high polarity of PAN polymers increases the hydrophilicity of the nanofibre layer. Unlike PAN, PVDF nanofibres are 

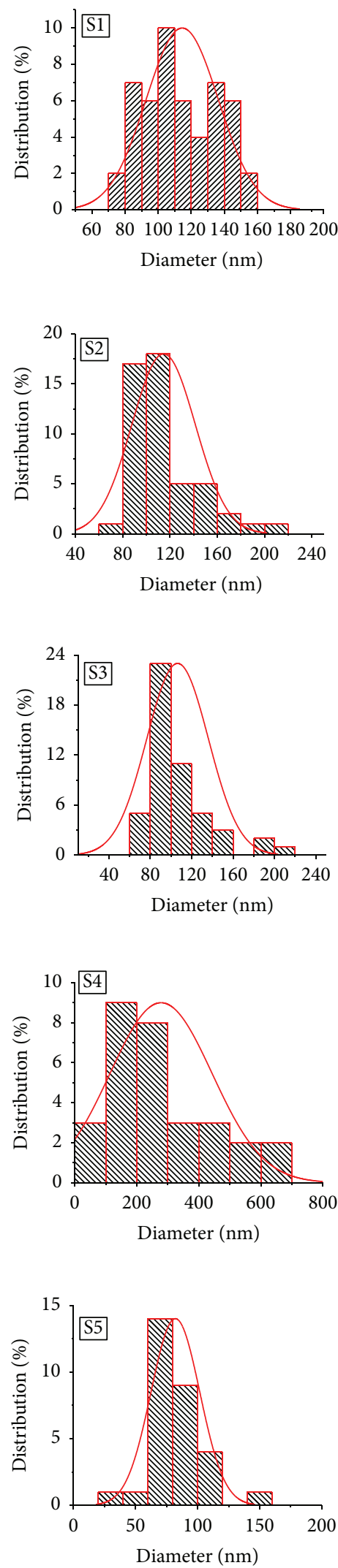

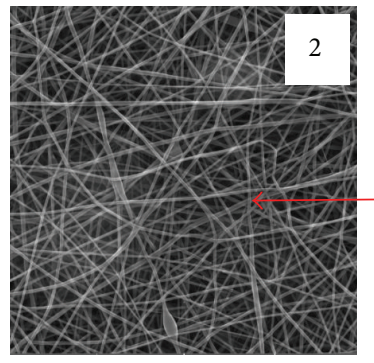

(a)
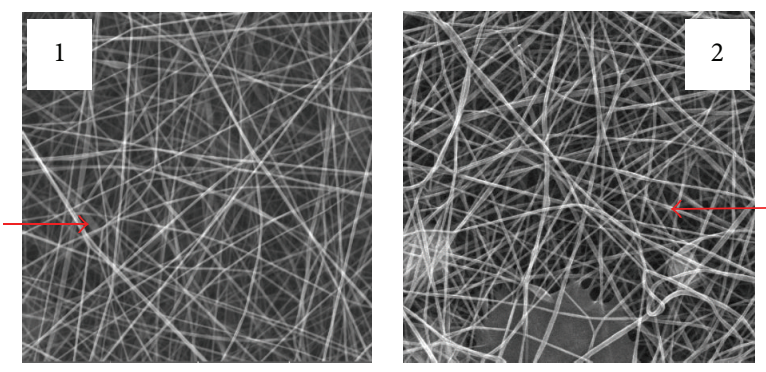

(b)

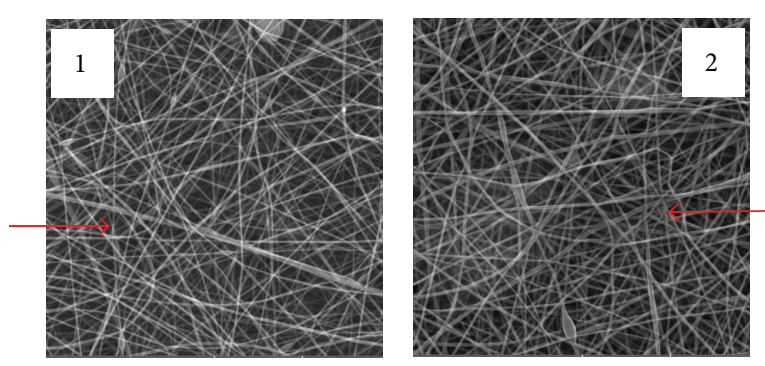

(c)
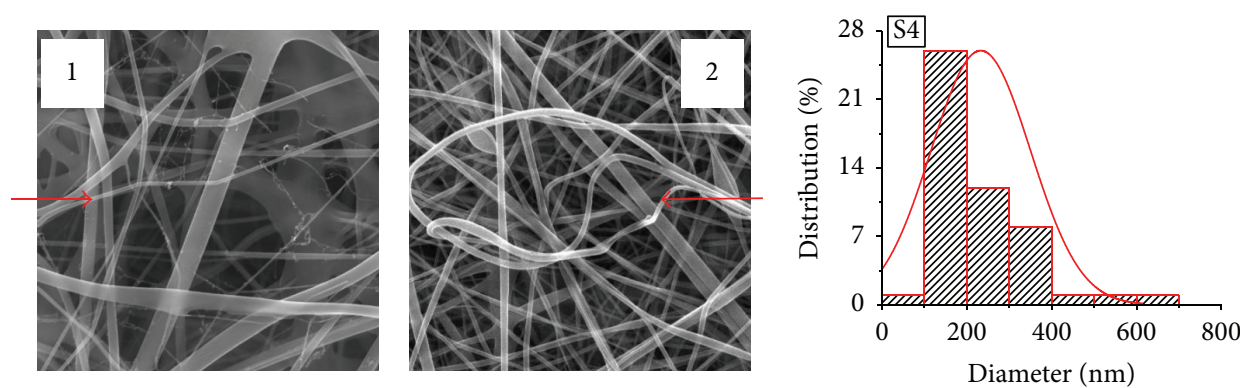

(d)
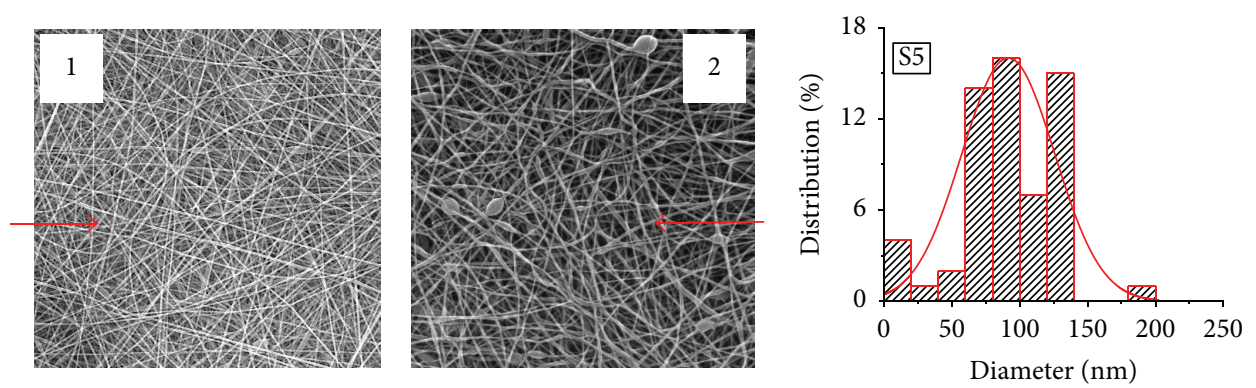

(e)

Figure 3: SEM images and fibre diameter distribution of samples (a) S1, (b) S2, (c) S3, (d) S4, and (e) S5 before (1) and after (2) the lamination process. 


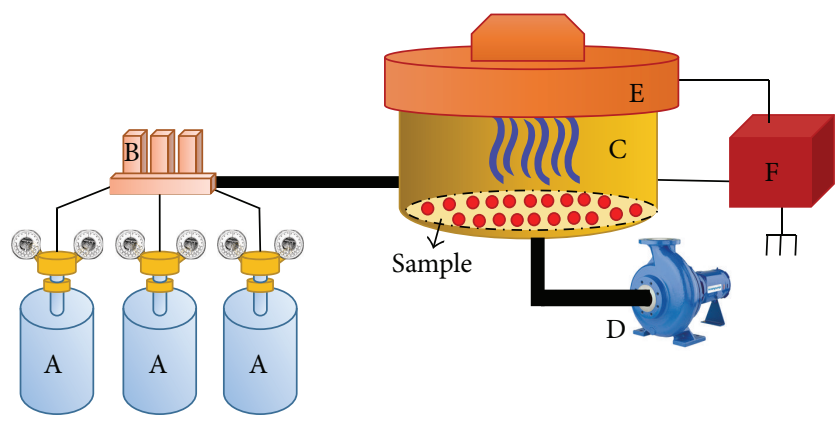

FIGURE 4: Diagram of the low-pressure vacuum MF plasma apparatus. The selected gases from the gas cylinders (A), connected to a mass flow controller (B), are controlling defined amount of gases to low-pressure vacuum plasma chamber (C) which is bound up with a vacuum pump (D). Defined work atmosphere is energized by MW (microwave) plasma head (E) which is powered by MW generator (F).

highly hydrophobic. PVDF polymers are durable and have high mechanical strength.

Low vacuum plasma treatment was used to change the hydrophilic structure of nanofibrous composite materials (Figure 4). Atmospheric air was used to increase the hydrophilicity of the nanofibres, whereas $\mathrm{SF}_{6}$ was used to raise the hydrophobicity of the samples. A period of 120 seconds was chosen as the safe irradiation time to prevent the degradation and etching of the nanofibrous surface.

Contact angle measurements for the untreated and plasma-treated nanofibrous composite membranes were performed to determine the effect of the treatments on the surface hydrophilicity. Figure 5 shows the difference between the contact angles of the composite nanofibrous membranes before and after plasma treatment in the first 20 seconds of contact time with water droplets.

PAN nanofibrous composite membranes have a hydrophilic nature with a contact angle of less than $90^{\circ}$ due to a high polarity backbone. On the other hand, the PVDF membranes are very hydrophobic with a contact angle of $131^{\circ}$. Increasing the amount of PAN in the PVDF decreased the contact angle of the material.

In the first experiment, atmospheric air was used to modify the surface of the membranes and increase the hydrophilicity. The hydrophilicity of the PVDF did not significantly improve. The results indicated that the low vacuum air plasma treatment is more effective for increasing the hydrophilicity layer on a hydrophilic base membrane. PAN nanofibre surfaces become more hydrophilic than PVDF due to the formation of high energy surface groups in reactions between the native surface groups of the polymer and the reactive plasma species.

In the second part of the experiment, $\mathrm{SF}_{6}$ gas was used for plasma enhancement to modify the hydrophobic surface. In general, fluorine-containing monomers are used to improve the hydrophobicity of the membranes [64-68]. Fluorine has a small atomic radius and the biggest electronegativity among atoms [69]. Figure 5 shows that plasma-treated PAN nanofibrous composite material has the highest hydrophobicity.
When the ratio of PVDF/PAN is $2 / 1$ and $1 / 1$, the hydrophobicity of the material showed the same contact angle as that with a pristine PVDF layer. On the other hand, when the ratio of PAN is higher than PVDF (PVDF/PAN 1/2), the hydrophobic surface improved. It can be concluded that the plasma treatment promoted the interaction between the monomer and the nanofibrous composite membrane surfaces, in particular for the hydrophilic base membranes. Similar results were also reported for various polymers [69-76]. It was found that $\mathrm{CF}_{4}$ plasma-treated polysulfone membranes show a higher contact angle than PVDF membranes [77]. The high surface polarity of PAN nanofibres showed significant surface modifications after plasma treatment, whereas PVDF has high chemical resistance to external chemicals or gases and showed less surface modification.

The increase in contact angle signifies a decrease in the wettability and hydrophilicity of the plasma-treated samples.

\section{Conclusion}

Various nanofibrous composite materials have been designed for possible application in areas of water treatment. PAN nanofibrous composite membranes showed hydrophilic characteristics, with a small fibre diameter of less than $100 \mathrm{~nm}$, while high mechanical strength PVDF nanofibrous composite membranes showed hydrophobic properties with thick nanofibres of around $250 \mathrm{~nm}$. PVDF nanofibres showed better thermal stability than PAN nanofibres. In order to benefit from both of the polymers, PVDF/PAN mixtures were prepared in various ratios. Various gasses were used for surface modification of the samples by low vacuum plasma treatment. The results indicate that the hydrophilic base membrane PAN showed better performance under plasma treatment. For instance, using atmospheric air, the contact angle of pristine PAN was reduced from $66.1^{\circ}$ to $25.5^{\circ}$, while slight changes in the contact angle of pristine PVDF were observed from $131^{\circ}$ to $123^{\circ}$. On the contrary, the hydrophobicity wasincreased using $\mathrm{SF}_{6}$ gasses. The contact angle of pristine PAN was increased from $66.1^{\circ}$ to $150^{\circ}$, while changes for the pristine PVDF were from $131^{\circ}$ to $140^{\circ}$. The contact angle of the mixture of PVDF/PAN nanofibres was mostly affected by the amount of PAN in the blend. It can be concluded that hydrophilic membranes have higher affinity to attach plasma particles compared to hydrophobic membranes.

\section{Competing Interests}

The authors declare that they have no competing interests.

\section{Acknowledgments}

The results of this project LO1201 were obtained through the financial support of the Ministry of Education, Youth and Sports in the framework of the targeted support of the "National Programme for Sustainability I" and the OPR\&DI 
Without treatment
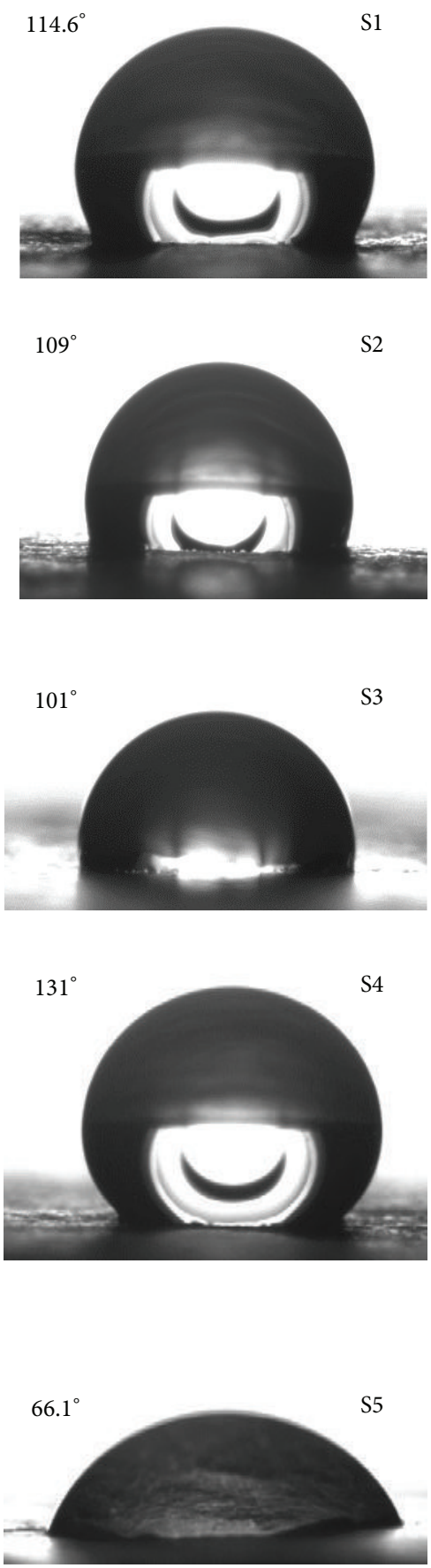

Air plasma-treated

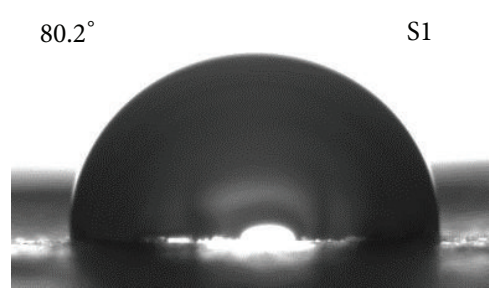

S2

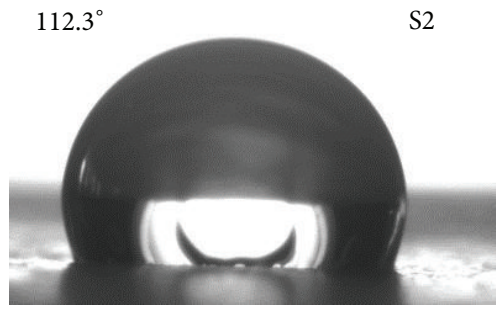

$38.1^{\circ}$

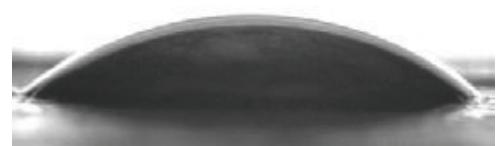

S4

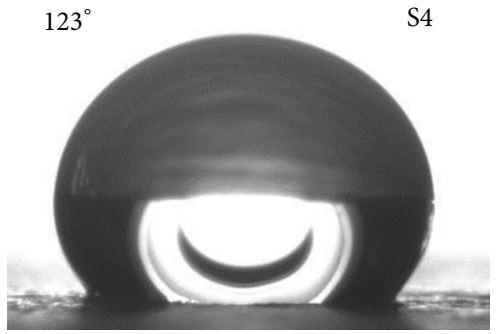

$25.5^{\circ}$

S5

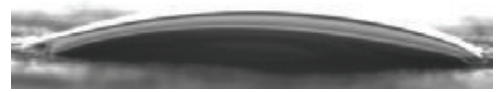

$\mathrm{SF}_{6}$ plasma-treated

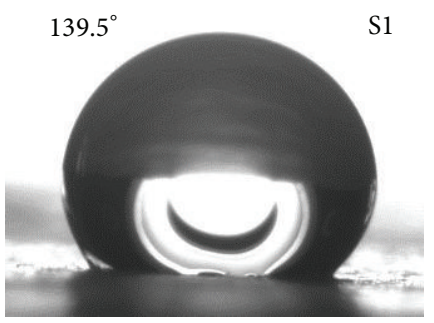

S2

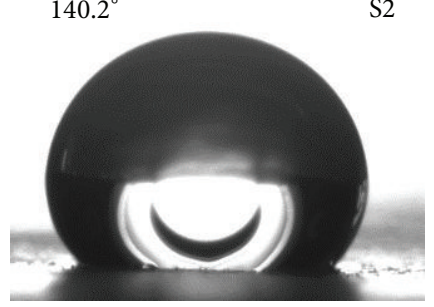

S3
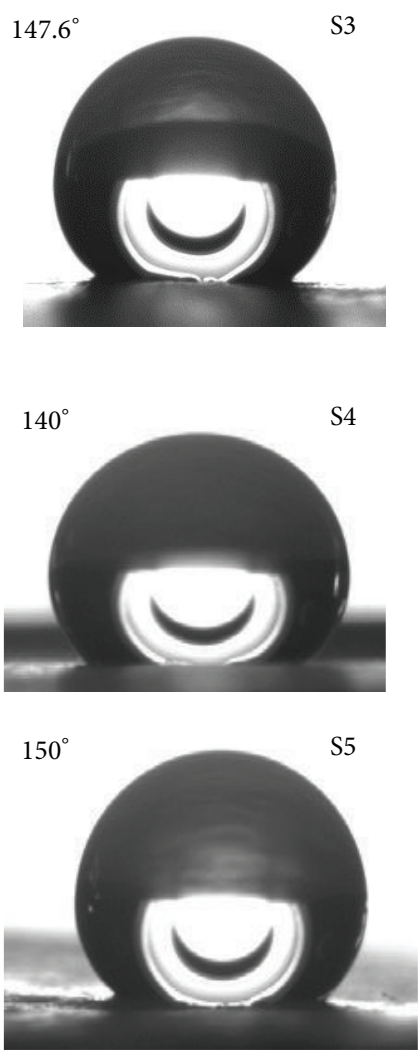

FIGURE 5: Changes in the contact angles of water droplets on the PAN, PVDF, and PVDF/PAN nanofibrous membranes without treatment and treated with air and with $\mathrm{SF}_{6}$ plasma.

Project Centre for Nanomaterials, Advanced Technologies and Innovation CZ.1.05/2.1.00/01.0005.

\section{References}

[1] F.-L. Zhou and R.-H. Gong, "Manufacturing technologies of polymeric nanofibres and nanofibre yarns," Polymer International, vol. 57, no. 6, pp. 837-845, 2008.
[2] A. Podgórski, A. Bałazy, and L. Gradoń, "Application of nanofibers to improve the filtration efficiency of the most penetrating aerosol particles in fibrous filters," Chemical Engineering Science, vol. 61, no. 20, pp. 6804-6815, 2006.

[3] T. Grafe and K. Graham, "Polymeric nanofibers and nanofiber webs: a new class of nonwovens," in Proceedings of the International Nonwovens Technical Conference: Joint INDA-TAPPI Conference (INTC '02), Atlanta, Ga, USA, September 2002. 
[4] N. Bhardwaj and S. C. Kundu, "Electrospinning: a fascinating fiber fabrication technique," Biotechnology Advances, vol. 28, no. 3, pp. 325-347, 2010.

[5] P. Gibson, H. Schreuder-Gibson, and D. Rivin, "Transport properties of porous membranes based on electrospun nanofibers," Colloids and Surfaces A: Physicochemical and Engineering Aspects, vol. 187-188, pp. 469-481, 2001.

[6] Woodhead Publishing Series in Textiles A2-Wei, Qufu, Functional Nanofibers and their Applications, Woodhead Publishing, pp. 15-19, 2012.

[7] M. Langner and A. Greiner, "Wet-laid meets electrospinning: nonwovens for filtration applications from short electrospun polymer nanofiber dispersions," Macromolecular Rapid Communications, vol. 37, no. 4, pp. 351-355, 2016.

[8] M. F. Li, D. Wang, R. Xiao, G. Sun, Q. H. Zhao, and H. Y. Li, "A novel high flux poly(trimethylene terephthalate) nanofiber membrane for microfiltration media," Separation and Purification Technology, vol. 116, pp. 199-205, 2013.

[9] R. S. Barhate and S. Ramakrishna, "Nanofibrous filtering media: filtration problems and solutions from tiny materials," Journal of Membrane Science, vol. 296, no. 1-2, pp. 1-8, 2007.

[10] S. Ouyang, T. Wang, X. Jia, Y. Chen, J. Yao, and S. Wang, "Self-indicating and recyclable superhydrophobic membranes for effective oil/water separation in harsh conditions," Materials \& Design, vol. 96, pp. 357-363, 2016.

[11] C.-W. Li, Q. Wang, J. Li et al., "Silver nanoparticles/chitosan oligosaccharide/poly(vinyl alcohol) nanofiber promotes wound healing by activating TGF $\beta 1 /$ Smad signaling pathway," International Journal of Nanomedicine, vol. 11, pp. 373-387, 2016.

[12] H. T. Bui, O. H. Chung, J. Dela Cruz, and J. S. Park, "Fabrication and characterization of electrospun curcumin-loaded polycaprolactone-polyethylene glycol nanofibers for enhanced wound healing," Macromolecular Research, vol. 22, no. 12, pp. 1288-1296, 2014.

[13] X. Z. Guang, C.-M. Moon, J.-S. Kwak, K.-W. Oh, H.-I. Bae, and J.-Y. Han, "Biomedical application of PHBV/collagen (PHCP) nanofiber as the wound dressing," Journal of Biomedical Research, vol. 12, no. 3, pp. 147-155, 2011.

[14] Z. W. Ma, M. Kotaki, R. Inai, and S. Ramakrishna, "Potential of nanofiber matrix as tissue-engineering scaffolds," Tissue Engineering, vol. 11, no. 1-2, pp. 101-109, 2005.

[15] Y. Mo, R. Guo, J. Liu et al., "Preparation and properties of PLGA nanofiber membranes reinforced with cellulose nanocrystals," Colloids and Surfaces B: Biointerfaces, vol. 132, pp. 177-184, 2015.

[16] I. Yalcin, J. Horakova, P. Mikes, T. G. Sadikoglu, R. Domin, and D. Lukas, "Design of polycaprolactone vascular grafts," Journal of Industrial Textiles, vol. 45, no. 5, pp. 813-833, 2016.

[17] M. J. Kim, J.-H. Kim, G. Yi, S.-H. Lim, Y. S. Hong, and D. J. Chung, "In vitro and in vivo application of PLGA nanofiber for artificial blood vessel," Macromolecular Research, vol. 16, no. 4, pp. 345-352, 2008.

[18] D. S. Katti, K. W. Robinson, F. K. Ko, and C. T. Laurencin, "Bioresorbable nanofiber-based systems for wound healing and drug delivery: optimization of fabrication parameters," Journal of Biomedical Materials Research-Part B: Applied Biomaterials, vol. 70, no. 2, pp. 286-296, 2004.

[19] R. L. Qi, R. Guo, M. W. Shen et al., "Electrospun poly(lacticco-glycolic acid)/halloysite nanotube composite nanofibers for drug encapsulation and sustained release," Journal of Materials Chemistry, vol. 20, no. 47, pp. 10622-10629, 2010.
[20] X. Chen, S. Guo, J. Li, G. Zhang, M. Lu, and Y. Shi, "Flexible piezoelectric nanofiber composite membranes as high performance acoustic emission sensors," Sensors and Actuators A: Physical, vol. 199, pp. 372-378, 2013.

[21] K. Kalinova, "A sound absorptive element comprising an acoustic resonance nanofibrous membrane," Recent Patents on Nanotechnology, vol. 9, no. 1, pp. 61-69, 2015.

[22] M. K. Ozturk, K. Kalinova, B. Nergis, and C. Candan, "Comparison of resonance frequency of a nanofibrous membrane and a homogeneous membrane structure," Textile Research Journal, vol. 83, no. 20, pp. 2204-2210, 2013.

[23] L. Mares, J. Svobodova, and F. Yalcinkaya, "Method for application of a cosmetic composition containing at least one active substance to skin and a means for carrying out this method for application of the cosmetic composition," WO2016/050227, Nafigate Cosmetics, A.S. (Pod pekárnami 245/10, Praha 9, 190 00, CZ), 2016.

[24] X. Zhang, L. Ji, O. Toprakci, Y. Liang, and M. Alcoutlabi, "Electrospun nanofiber-based anodes, cathodes, and separators for advanced lithium-ion batteries," Polymer Reviews, vol. 51, no. 3, pp. 239-264, 2011.

[25] J. Xu, L. Wang, J. Guan, and S. Yin, "Coupled effect of strain rate and solvent on dynamic mechanical behaviors of separators in lithium ion batteries," Materials \& Design, vol. 95, pp. 319-328, 2016.

[26] Y. Liao, R. Wang, M. Tian, C. Qiu, and A. G. Fane, "Fabrication of polyvinylidene fluoride (PVDF) nanofiber membranes by electro-spinning for direct contact membrane distillation," Journal of Membrane Science, vol. 425-426, pp. 30-39, 2013.

[27] C. Feng, K. C. Khulbe, T. Matsuura et al., "Production of drinking water from saline water by air-gap membrane distillation using polyvinylidene fluoride nanofiber membrane," Journal of Membrane Science, vol. 311, no. 1-2, pp. 1-6, 2008.

[28] J. A. Prince, D. Rana, G. Singh, T. Matsuura, T. Jun Kai, and T. S. Shanmugasundaram, "Effect of hydrophobic surface modifying macromolecules on differently produced PVDF membranes for direct contact membrane distillation," Chemical Engineering Journal, vol. 242, pp. 387-396, 2014.

[29] L. D. Tijing, Y. C. Woo, W.-G. Shim et al., "Superhydrophobic nanofiber membrane containing carbon nanotubes for highperformance direct contact membrane distillation," Journal of Membrane Science, vol. 502, pp. 158-170, 2016.

[30] Z.-Q. Dong, X.-H. Ma, Z.-L. Xu, and Z.-Y. Gu, "Superhydrophobic modification of $\mathrm{PVDF}-\mathrm{SiO}_{2}$ electrospun nanofiber membranes for vacuum membrane distillation," RSC Advances, vol. 5, no. 83, pp. 67962-67970, 2015.

[31] J. F. Liu, J. J. Liu, H. Y. Xu et al., "Novel tumor-targeting, selfassembling peptide nanofiber as a carrier for effective curcumin delivery," International Journal of Nanomedicine, vol. 9, no. 1, pp. 197-207, 2014.

[32] H. H. Henrichsen, J. Kjelstrup-Hansen, D. Engstrøm, C. H. Clausen, P. Bøggild, and H.-G. Rubahn, "Electrical conductivity of organic single-nanofiber devices with different contact materials," Organic Electronics, vol. 8, no. 5, pp. 540-544, 2007.

[33] C. S. Sharma, H. Katepalli, A. Sharma, and M. Madou, "Fabrication and electrical conductivity of suspended carbon nanofiber arrays," Carbon, vol. 49, no. 5, pp. 1727-1732, 2011.

[34] R. L. Poveda and N. Gupta, "Electrical properties of carbon nanofiber reinforced multiscale polymer composites," Materials and Design, vol. 56, pp. 416-422, 2014.

[35] X. Wang, K. Zhang, Y. Yang et al., "Development of hydrophilic barrier layer on nanofibrous substrate as composite membrane 
via a facile route," Journal of Membrane Science, vol. 356, no. 1-2, pp. 110-116, 2010.

[36] S. Kiani, S. M. Mousavi, N. Shahtahmassebi, and E. Saljoughi, "Hydrophilicity improvement in polyphenylsulfone nanofibrous filtration membranes through addition of polyethylene glycol," Applied Surface Science, vol. 359, pp. 252-258, 2015.

[37] S. J. Cho, S. M. Jung, M. Kang, H. S. Shin, and J. H. Youk, "Preparation of hydrophilic PCL nanofiber scaffolds via electrospinning of PCL/PVP-b-PCL block copolymers for enhanced cell biocompatibility," Polymer, vol. 69, no. 1, pp. 95-102, 2015.

[38] L. Zarybnicka, E. Stranska, J. Machotova, and G. Lencova, "Preparation of two-layer anion-exchange poly(ethersulfone) based membrane: effect of surface modification," International Journal of Polymer Science, vol. 2016, Article ID 8213694, 8 pages, 2016.

[39] K. H. Lee, G. H. Kwon, S. J. Shin et al., "Hydrophilic electrospun polyurethane nanofiber matrices for hMSC culture in a microfluidic cell chip," Journal of Biomedical Materials Research Part A, vol. 90, no. 2, pp. 619-628, 2009.

[40] A. Abdal-Hay, K. H. Hussein, L. Casettari, K. A. Khalil, and A. S. Hamdy, "Fabrication of novel high performance ductile poly(lactic acid) nanofiber scaffold coated with poly(vinyl alcohol) for tissue engineering applications," Materials Science and Engineering C, vol. 60, pp. 143-150, 2016.

[41] N. Recek, M. Resnik, H. Motaln et al., "Cell adhesion on polycaprolactone modified by plasma treatment," International Journal of Polymer Science, vol. 2016, Article ID 7354396, 9 pages, 2016.

[42] S. H. Kim, S. Y. Jeon, P. J. Yoo, L. S. Pu, and J. Y. Lee, "Metal oxide/polymer hybrid nanofiber as flexible moisture absorbent," Fibers and Polymers, vol. 14, no. 12, pp. 1975-1980, 2013.

[43] J. Zhao, N. Dehbari, W. Han, L. Huang, and Y. Tang, "Electrospun multi-scale hybrid nanofiber/net with enhanced water swelling ability in rubber composites," Materials and Design, vol. 86, pp. 14-21, 2015.

[44] S. Maretschek, A. Greiner, and T. Kissel, "Electrospun biodegradable nanofiber nonwovens for controlled release of proteins," Journal of Controlled Release, vol. 127, no. 2, pp. 180$187,2008$.

[45] F. Yalcinkaya, M. Komarek, D. Lubasova, F. Sanetrnik, and J. Maryska, "Preparation of antibacterial nanofibre/nanoparticle covered composite yarns," Journal of Nanomaterials, vol. 2016, Article ID 7565972, 7 pages, 2016.

[46] F. Yener, B. Yalcinkaya, and O. Jirsak, "On the measured current in needle- and needleless electrospinning," Journal of Nanoscience and Nanotechnology, vol. 13, no. 7, pp. 4672-4679, 2013.

[47] F. Yalcinkaya, B. Yalcinkaya, and O. Jirsak, "Influence of salts on electrospinning of aqueous and nonaqueous polymer solutions," Journal of Nanomaterials, vol. 2015, Article ID 134251, 12 pages, 2015.

[48] F. Yener and O. Jirsak, "Improving performance of polyvinyl butyral electrospinning," in Proceedings of the 3rd International Conference on NANOCON, Brno, Czech Republic, September 2011.

[49] F. Yener and O. Jirsak, "Comparison between the needle and roller electrospinning of polyvinylbutyral," Journal of Nanomaterials, vol. 2012, Article ID 839317, 6 pages, 2012.

[50] F. Cengiz, T. A. Dao, and O. Jirsak, "Influence of solution properties on the roller electrospinning of poly(vinyl alcohol)," Polymer Engineering and Science, vol. 50, no. 5, pp. 936-943, 2010.
[51] F. Cengiz and O. Jirsak, "The effect of salt on the roller electrospinning of polyurethane nanofibers," Fibers and Polymers, vol. 10, no. 2, pp. 177-184, 2009.

[52] L. Chen, L. Bromberg, H. Schreuder-Gibson, J. Walker, T. A. Hatton, and G. C. Rutledge, "Chemical protection fabrics via surface oximation of electrospun polyacrylonitrile fiber mats," Journal of Materials Chemistry, vol. 19, no. 16, pp. 2432-2438, 2009.

[53] Y.-Q. Wang, H.-X. Huang, B. Li, and W.-S. Li, "Novelly developed three-dimensional carbon scaffold anodes from polyacrylonitrile for microbial fuel cells," Journal of Materials Chemistry A, vol. 3, no. 9, pp. 5110-5118, 2015.

[54] N. Kizildag and N. Ucar, "Nanocomposite polyacrylonitrile filaments with electrostatic dissipative and antibacterial properties," Journal of Composite Materials, 2016.

[55] N. Kizildag and N. Ucar, "Investigation of the properties of PAN/f-MWCNTs/AgNPs composite nanofibers," Journal of Industrial Textiles, 2016.

[56] Y. Xia and Y. Lu, "Conductive polymers/polyacrylonitrile composite fibers: fabrication and properties," Polymer Composites, vol. 31, no. 2, pp. 340-346, 2010.

[57] I. Shimada, T. Takahagi, M. Fukuhara, K. Morita, and A. Ishitani, "FT-IR study of the stabilization reaction of polyacrylonitrile in the production of carbon fibers," Journal of Polymer Science, Part A: Polymer Chemistry, vol. 24, no. 8, pp. 1989-1995, 1986.

[58] S. Madakbaş, E. Çakmakçi, and M. V. Kahraman, "Preparation and thermal properties of polyacrylonitrile/hexagonal boron nitride composites," Thermochimica Acta, vol. 552, pp. 1-4, 2013.

[59] C. Merlini, M. D. O. Barra, D. A. da Silva Ramôa et al., "Electrically conductive polyaniline-coated electrospun poly (vinylidene fluoride) mats," Frontiers in Materials, vol. 2, article 14, 2015.

[60] A. L. Gomes, M. B. Pinto Zakia, J. G. Filho, E. Armelin, C. Alemán, and J. Sinezio de Carvalho Campos, "Preparation and characterization of semiconducting polymeric blends. Photochemical synthesis of poly(3-alkylthiophenes) using host microporous matrices of poly(vinylidene fluoride)," Polymer Chemistry, vol. 3, no. 5, pp. 1334-1343, 2012.

[61] J. Matulevicius, L. Kliucininkas, D. Martuzevicius, E. Krugly, M. Tichonovas, and J. Baltrusaitis, "Design and characterization of electrospun polyamide nanofiber media for air filtration applications," Journal of Nanomaterials, vol. 2014, Article ID 859656, 13 pages, 2014.

[62] J. Li, F. Gao, L. Q. Liu, and Z. Zhang, "Needleless electro-spun nanofibers used for filtration of small particles," Express Polymer Letters, vol. 7, no. 8, pp. 683-689, 2013.

[63] S. Kaur, S. Sundarrajan, D. Rana, T. Matsuura, and S. Ramakrishna, "Influence of electrospun fiber size on the separation efficiency of thin film nanofiltration composite membrane," Journal of Membrane Science, vol. 392-393, pp. 101-111, 2012.

[64] E. C. Rangel, W. C. A. Bento, M. E. Kayama, W. H. Schreiner, and N. C. Cruz, "Enhancement of polymer hydrophobicity by SF6 plasma treatment and argon plasma immersion ion implantation," Surface and Interface Analysis, vol. 35, no. 2, pp. 179-183, 2003.

[65] P. Chaivan, N. Pasaja, D. Boonyawan, P. Suanpoot, and T. Vilaithong, "Low-temperature plasma treatment for hydrophobicity improvement of silk," Surface and Coatings Technology, vol. 193, no. 1-3, pp. 356-360, 2005.

[66] I. Woodward, W. C. E. Schofield, V. Roucoules, and J. P. S. Badyal, "Super-hydrophobic surfaces produced by plasma 
fluorination of polybutadiene films," Langmuir, vol. 19, no. 8, pp. 3432-3438, 2003.

[67] R. A. Simão, M. L. V. J. da Silva, M. Martins, R. M. S. M. Thiré, and C. T. Andrade, "Sulphur hexafluoride plasma treatment to enhance the hydrophobicity of CVD carbon coatings produced on cornstarch plasticized films," Macromolecular Symposia, vol. 245-246, no. 1, pp. 519-524, 2006.

[68] D. C. Bastos, A. E. F. Santos, M. L. V. J. da Silva, and R. A. Simão, "Hydrophobic corn starch thermoplastic films produced by plasma treatment," Ultramicroscopy, vol. 109, no. 8, pp. 10891093, 2009.

[69] L. Liu, F. Shen, X. Chen et al., "A novel plasma-induced surface hydrophobization strategy for membrane distillation: etching, dipping and grafting," Journal of Membrane Science, vol. 499, pp. 544-554, 2016.

[70] S. Inbakumar, R. Morent, N. de Geyter et al., "Chemical and physical analysis of cotton fabrics plasma-treated with a low pressure DC glow discharge," Cellulose, vol. 17, no. 2, pp. 417426, 2010.

[71] K. Yoshihisa, A. Yoshimura, Y. Shibamori, K. Fuchigami, and N. Kubota, "Hydrophilic modification of plastic surface by using microwave plasma irradiation," IHI Engineering Review, vol. 46, no. 1, pp. 29-33, 2013.

[72] A. Bismarck, W. Brostow, R. Chiu, H. E. Hagg Lobland, and K. K. C. Ho, "Effects of surface plasma treatment on tribology of thermoplastic polymers," Polymer Engineering \& Science, vol. 48, no. 10, pp. 1971-1976, 2008.

[73] D. Hegemann, H. Brunner, and C. Oehr, "Plasma treatment of polymers for surface and adhesion improvement," Nuclear Instruments and Methods in Physics Research, Section B: Beam Interactions with Materials and Atoms, vol. 208, no. 1-4, pp. 281286, 2003.

[74] C. Borcia, G. Borcia, and N. Dumitrascu, "Plasma induced surface modification in relation to polymer characteristics," Journal of Optoelectronics and Advanced Materials, vol. 10, no. 3, pp. 675-679, 2008.

[75] C. Borcia, G. Borcia, and N. Dumitrascu, "Relating plasma surface modification to polymer characteristics," Applied Physics A: Materials Science and Processing, vol. 90, no. 3, pp. 507-515, 2008.

[76] C. Borcia, G. Borcia, and N. Dumitrascu, "Surface treatment of polymers by plasma and Uv radiation," Romanian Journal of Physics, vol. 56, no. 1-2, pp. 224-232, 2011.

[77] M. Tian, Y. Yin, C. Yang et al., " $\mathrm{CF}_{4}$ plasma modified highly interconnective porous polysulfone membranes for direct contact membrane distillation (DCMD)," Desalination, vol. 369, pp. 105-114, 2015. 

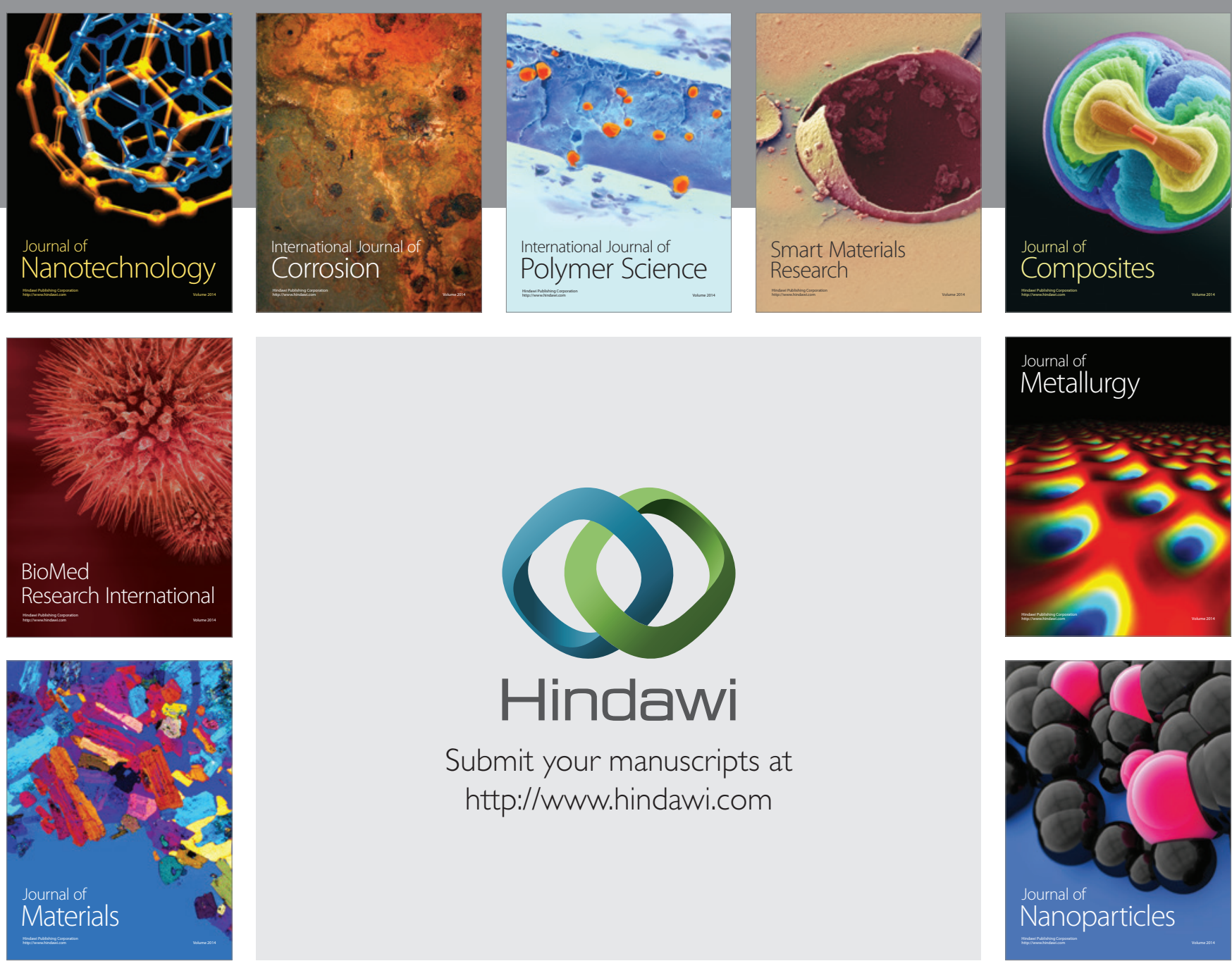

\section{Hindawi}

Submit your manuscripts at

http://www.hindawi.com

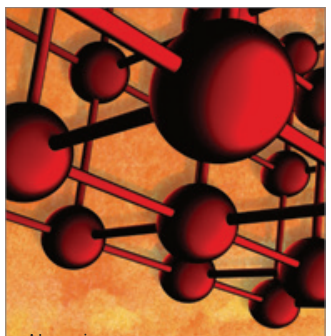

Materials Science and Engineering
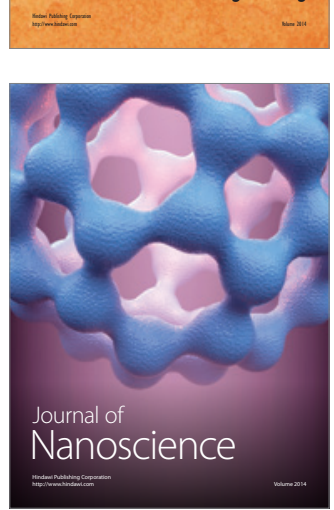
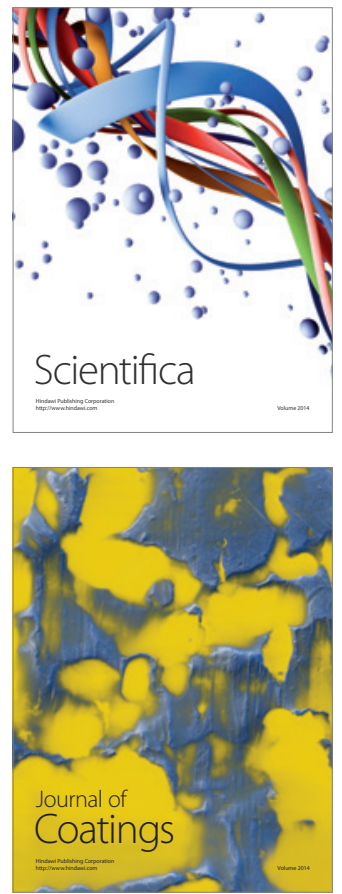
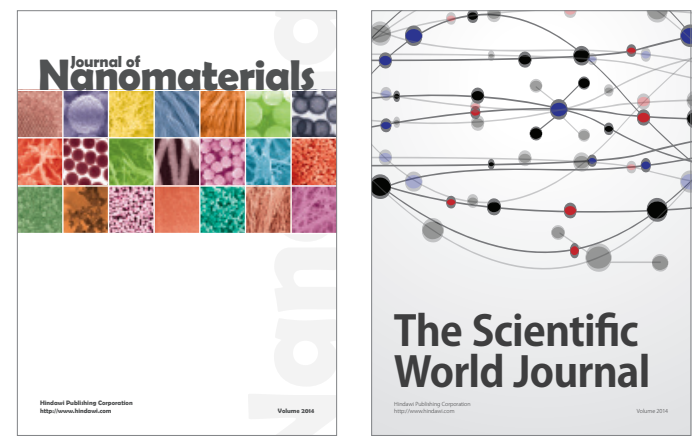

The Scientific World Journal
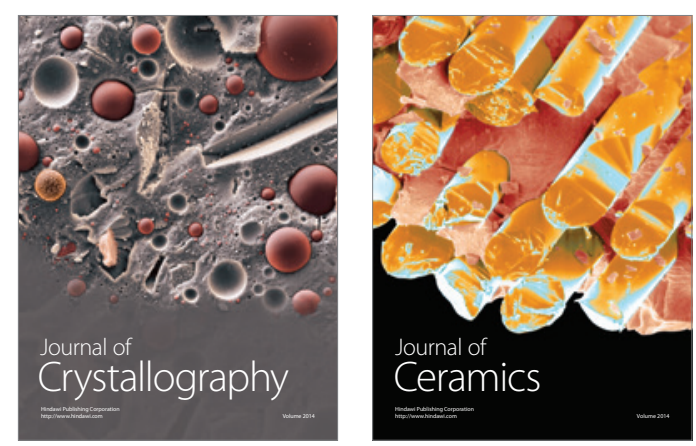
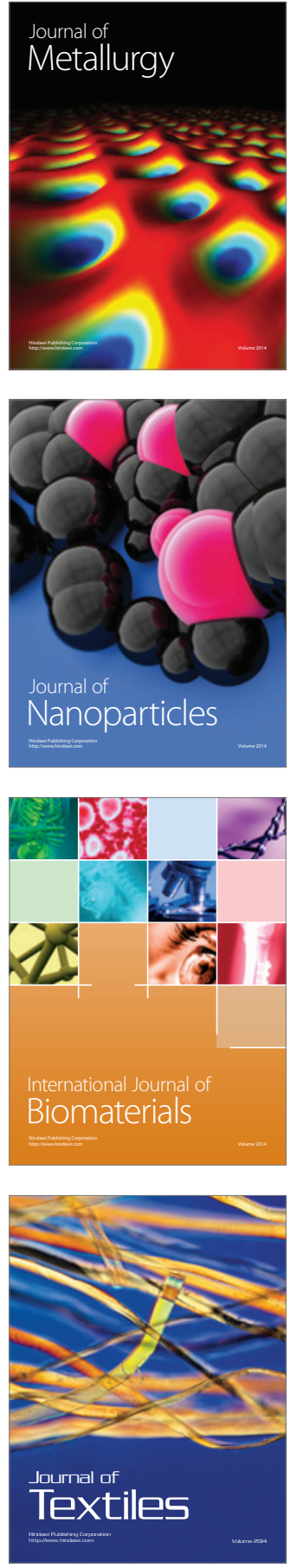